\title{
ARTICLES
}

\section{THE EFFECTIVENESS OF STRUCTURED TEACHING PROGRAMME ON KNOWLEDGE AND PRACTICE REGARDING ENVIRONMENTAL AND PERSONAL HYGIENE AMONG SCHOOL CHILDREN}

\section{Mr. Manish Saxena* I Dr. Rajendra Prasad Sharma**}

*Ph.D Scholar \& Assistant Professor, Upchar College of Nursing, Jaipur, Rajasthan, India.

**Associate Professor, Mahatma Gandhi Nursing College Jaipur, Rajasthan, India

DOI: http://doi.org/10.47211/idcij.2021.v08i03.003

\begin{abstract}
A study regarding poor hygiene and inadequate sanitary conditions play major roles in the increased burden of communicable diseases. The study evaluated the knowledge, attitude, practice of hygiene among rural school children in Ethiopia; about 669 students were in grades 1-6, and they were interviewed by trained staff. Data consisted of hygiene and hand washing practices, knowledge about sanitation, personal hygiene characteristics. Approximately 52\% of students were having adequate knowledge of hygiene, only $36.2 \%$ reported using soap, and of the $76.7 \%$ of students who reported hand washing after defecation, only $14.8 \%$ reported actually following this practice. Study findings underscore the need for more hand washing and hygiene education in schools. The first concept in personal hygiene is the positive and negative emotions that affect physical health, such as feeling pride in being neat and clean or feeling frustration in using hygiene tools. The second concept is personal hygiene practices such as hand washing, oral hygiene etc. The third concept is the fact that germs can lead to common diseases such as the flu or a cold. Nurses can use various techniques to help kids remember these.
\end{abstract}

Key Words: Personal Hygiene, Cleanliness, Environment, Children's.

\section{About Authors}

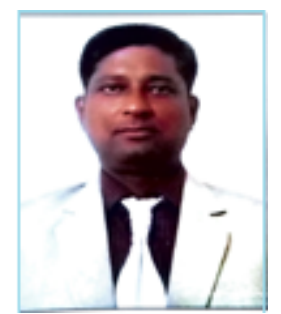

Author Mr. Manish Saxena is currently working as Associate Professor and Vice Principal at Upchar College of Nursing, Jaipur, Rajasthan, India.

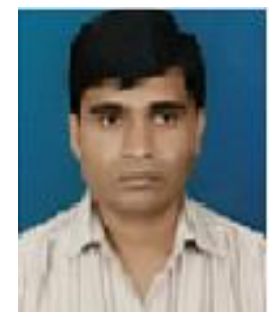

Author Dr. Rajendra Prasad Sharma is currently working as Associate Professor at Mahatma Gandhi Nursing College Jaipur, Rajasthan, India. He is also a Research Guide for PG and Ph.D. Scholars. He has presented papers at various seminars and conferences 


\section{INTRODUCTION}

Environmental and personal hygiene are important in every stage of life, but good cleanliness habits start in childhood. Kids who learn what it is and how to follow proper hygiene practices will usually carry that into adulthood. Hygiene education starts with the family, and eventually youngsters can learn what to do and follow cleanliness rules on their own when a baby makes the transition into childhood, it may be more of a challenge to keep her fresh. As a child grows, so do his opportunities for the face, hands and feet to become messy and dirty. Learning proper cleanliness skills in childhood can help prevent the spread of germs and illness. As a child grows, good hygiene becomes increasingly important because hormonal changes during puberty lead to stronger odour and oilier hair and skin.

Discussing environmental and personal hygiene is something most people prefer to avoid. After all, it can be tricky to let someone know that his/ her hygiene is lacking without giving offense. In school, teachers often find themselves having to instruct students on the importance of good hygiene. Teaching the basics of proper personal hygiene is important for keeping kids healthy and clean. Children with poor hygiene often suffer from health problems. They may be ostracised and ridiculed by their peers, as well. To avoid damaging the student's self-esteem, a teacher must broach the subject of personal hygiene carefully.

The environmental personal hygiene habits developed by child can be taught in a fun way. Making up of games to see if child can remember what steps are needed to accomplish a specific hygiene goal. Using creativity and imagination will help child maintain an interest in environmental and personal hygiene. Charts, graphs, humour stickers, puppets or songs are some ideas to use to motivate the child. Care must be there for not making environmental and personal hygiene too much work for a child. Keep it light and fun as the child transitions into owning these habits for a lifetime. Consistency in good hygiene can help the child establish healthy habits for a lifetime.

\section{NEED FOR THE STUDY}

Environmental and personal hygiene refer to the cleaning and grooming of the world safety. In addition to improving appearance, environmental and personal hygiene is an important form of protection against disease and infections of all kinds. Understanding the importance of environmental and personal hygiene allows the children to make informed decisions about how to care for their health and appearance. The main purpose of environmental and personal hygiene is to prevent illness and improve appearance, but hygiene also plays an important role in social acceptance and can either improve or hinder a person's reputation in social situations. Bad breath, body odour and an unkempt appearance, for example, are often considered undesirable and can give a bad first impression to peers, acquaintances and potential mates.

India has one of the largest groups of school going children, especially in rural areas. There are about 6.3 lakhs rural schools both primary and upper primary, with 80 million school going children. But it is also a fact that only 8 percent of schools have the sanitation facilities in school premises. Out of 6.3 lakhs primary and upper primary rural schools, only 44 percent have water supply facilities. 19 percent have urinals and 8 percent have lavatory facilities. Only 19 percent have separate urinals and 4 percent have lavatory facility for girls. Under these conditions, schools and community environment become unsafe places where diseases are transmitted.

\section{OBJECTIVES}

- To assess the Pre-test knowledge and practice levels of primary school children regarding environmental and personal hygiene.

- To assess the Post-test knowledge and practice levels of primary school children regarding environmental and personal hygiene.

- To evaluate the effectiveness of the structured teaching programme on environmental and personal hygiene by comparing the Pre-test and Post-test knowledge scores. 


\section{ARTICLES}

- $\quad$ To find the correlation between knowledge and practice regarding environmental and personal hygiene among school children.

- To find out the association between Pre-test knowledge levels of Primary school children regarding environmental and personal hygiene with their selected socio-demographic variables.

\section{HYPOTHESIS}

$\mathbf{H}_{\mathbf{1}}$ - The Post-test mean knowledge score will be higher than the Pre-test mean knowledge score regarding environmental and personal hygiene among primary school children.

$\mathbf{H}_{\mathbf{2}}$ - There will be significant association between Pre-test knowledge levels of school children regarding environmental and personal hygiene with their selected socio-demographic variables.

$\mathbf{H}_{\mathbf{3}}$ - There will be no significant association between knowledge scores and practice scores.

\section{RESULTS}

This chapter deals with the statistical analysis, which is a method of rendering quantitative information in a meaningful and intelligible manner. Statistical procedure of the data gathered to assess the knowledge regarding environmental and personal hygiene among primary school children studying in rural schools, enables the researcher to organise, interpret and communicate information meaningfully.

Table .1: Frequency and percentage distribution of Socio-demographic variables

\begin{tabular}{|l|l|c|c|}
\hline \multirow{4}{*}{ Characteristics } & \multirow{2}{*}{ Category } & Respondents & Characteristics \\
\cline { 2 - 4 } & & Number & Percent \\
\hline \multirow{4}{*}{ Age group (years) } & $07-08$ & 18 & 30.0 \\
\cline { 2 - 4 } & $08-09$ & 18 & 30.0 \\
\cline { 2 - 4 } & $09-10$ & 13 & 21.5 \\
\cline { 2 - 4 } & $>10$ & 11 & 18.3 \\
\hline \multirow{3}{*}{ Religion } & Boys & 6 & 10.0 \\
\cline { 2 - 4 } & Girls & 54 & 90.0 \\
\hline \multirow{3}{*}{ Class } & Hindu & 42 & 70.0 \\
\cline { 2 - 4 } & Muslim & 18 & 30.0 \\
\hline \multirow{3}{*}{ Parent Education } & $3^{\text {rd }}$ Student & 44 & 73.3 \\
\cline { 2 - 4 } & $4^{\text {th }}$ and $5^{\text {th }}$ Student & 16 & 26.7 \\
\hline \multirow{3}{*}{ Monthly income of the family } & Below $5^{\text {th }}$ Student & 41 & 68.3 \\
\cline { 2 - 4 } & $6^{\text {th }}-9^{\text {th }}$ Student & 13 & 21.7 \\
\cline { 2 - 4 } & $10^{\text {th }}-12^{\text {th }}$ Student & 6 & 10.0 \\
\hline & Rs.5001 -10000 & 31 & 51.7 \\
\hline & Joint & 29 & 48.3 \\
\cline { 2 - 4 } & Nuclear & 34 & 56.7 \\
\hline & & 26 & 43.3 \\
\hline
\end{tabular}




\section{ARTICLES}

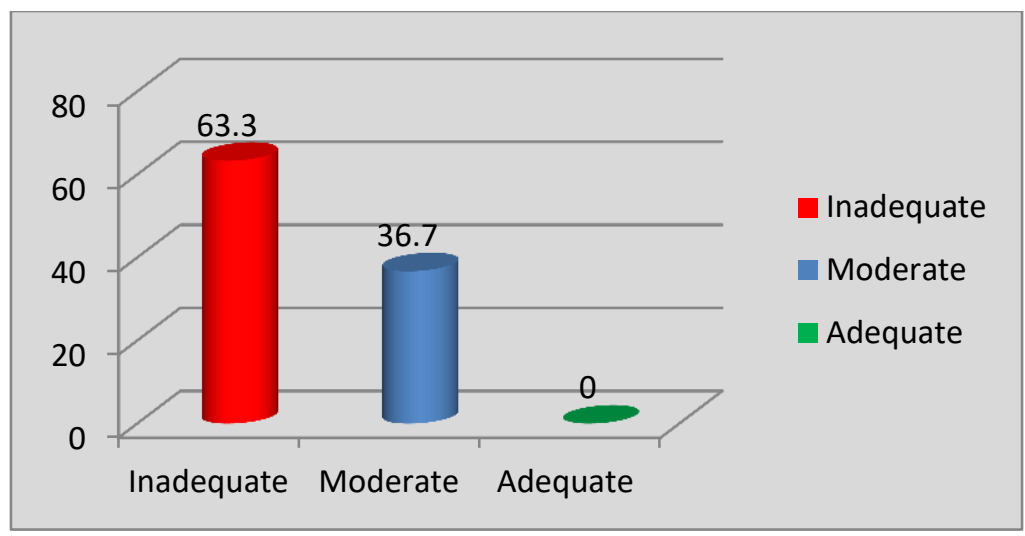

Figure .1: Percentage distribution of children on Pre-test knowledge level regarding environmental and personal hygiene

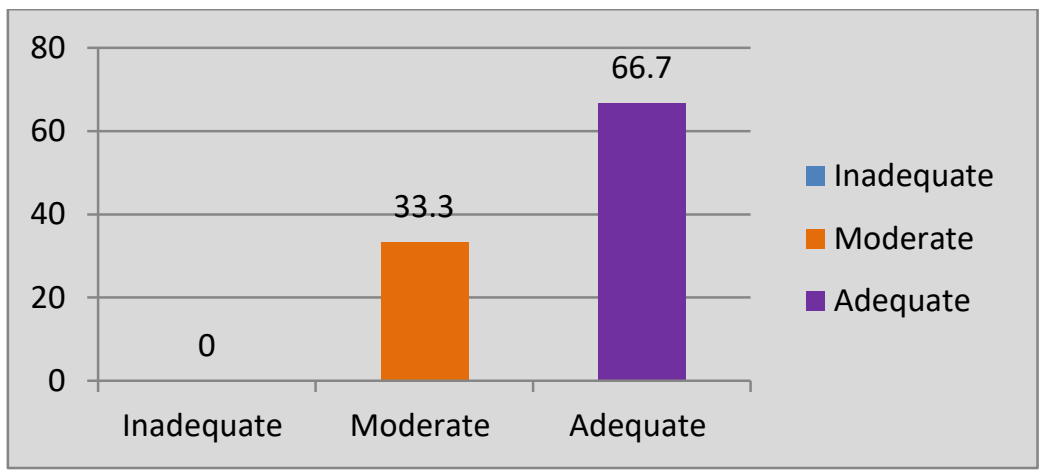

Figure .2: Classification of respondents on Post-test knowledge level of structured teaching programme regarding environmental and personal hygiene

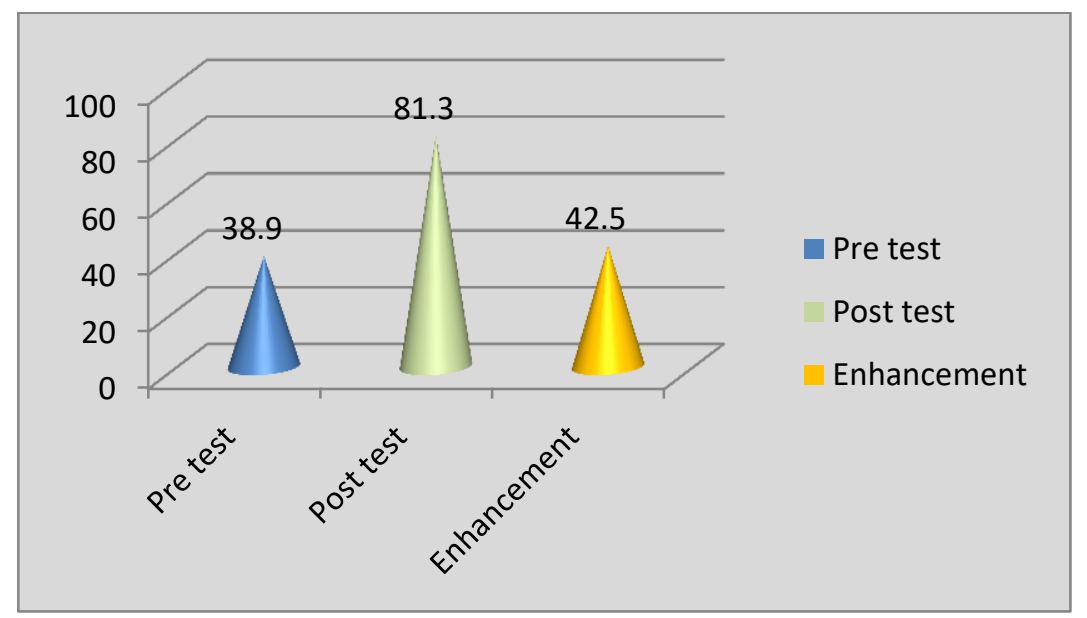

Figure .3: Overall Pre-test and Post-test Mean Knowledge on structured teaching programme regarding environmental and personal hygiene 


\section{ARTICLES}

The Chi-square test was carried out to determine the association between the pre-test knowledge of children and their demographic variables such as age, gender, religion, class, parents' education, type of family, monthly income. Out of these age $\left(\pi^{2}=5.48^{*}\right)$ was found to be significantly associated with pre-test knowledge of $5 \%$ level and the rest of the demographic variables were not significant. Hence research hypotheses $\mathbf{H}_{\mathbf{2}}$ is proved and accepted.

\section{CONCLUSION}

Childhood illness is a pervasive developmental disorder that affects children's social, physical and behavioural development. There are qualitative impairments in social interaction, communication with restricted repetitive and stereotyped patterns of behaviour, interests and activities. Knowledge and awareness about environmental and personal hygiene have been on the increase, especially in the developing countries whereas these remain at developed countries. Lack of knowledge and awareness about environmental and personal hygiene in childhood is thus a major barrier to improving the health and wellbeing of children affected by infections \& illnesses.

\section{REFERENCES}

1. K. Park. Textbook of preventive and social medicine. M/s Banarasidas Bhanot publishers, Jabalpur 16/ ed, 2000.

2. United Nations Population Information Network (POPIN). Guidelines on Reproductive Health. Available from URL: http://www.undp.org/popin.

3. Jharkhand M S, A Report on Menstrual Hygiene Management, UNICEF, Jharkhand in 2009.

4. Dasgupta A and Sarkar M. "Menstrual Hygiene: How Hygienic is the adolescent girl?" The Indian Journal of Community Medicine in India. 2008 April; 33 (2):77-80.

5. Shabnam O, Khyrunnia B. "Factors influencing hygiene practices during menses among childrens friom south India". DOS in Food Science \& Nutrition University of Mysore, Manasagangotri, Mysore, India 2010, 2(12); P:411423.

6. THE TIMES OF INDIA, online edition of Indian's National Newspaper. "Feminine hygiene care in India, and rampant unhygienic sanitary practices", in India, 2011 May 11.

7. http://www.ncbi.nlm.nih.gov/pubmed/21505773

8. Rajini Dhingra, Anil Kumar and Manpreet Kour. "Knowledge and practices related to Menstruation among Tribal (Gujjar) adolescent girls. P.G. Department of Home Science. University of Jammu. India. 2009. Ethno-Med, 3(1):43-48(2009). 